\title{
Analisis Dampak Peningkatan Laju Pertumbuhan Penduduk (Data SP2020) Terhadap Pengendalian Kuantitas Penduduk di Nusa Tenggara Barat
}

\author{
${ }^{*}$ Helmy Fuadi \\ Fakultas Ekonomi dan Bisnis, Universitas Mataram \\ *Coresponding Email: helmyfuadi@yahoo.co.id
}

\section{Info Artikel}

Kata Kunci:

Pengendalian Kuantitas Penduduk

\section{ABSTRAK}

Berdasarkan data Sunsus Penduduk (SP) tahun 2020, Nusa Tenggara Barat adalah salah satu provinsi di Indonesia diluar pulau Jawa yang mengalami pertumbuhan penduduk cukup signifikan. Berdasarkan proyeksi penduduk menggunakan SUPAS, diperkirakan laju pertumbuhan penduduk (LPP) sampai dengan 2015-2035 menurun dibawah 1.17, namun dari hasil Sensus Penduduk ternyata LPP meningkat menjadi 1.63. Selain LPP juga angka kelahiraan total (TFR) meningkat dari 2,4 menjadi 2.9.

Pertambahan penduduk Nusa Tenggara Barat yang cenderung terus meningkat dari tahun ke tahun tersebut akan menimbulkan berbagai persoalan yang semakin kompleks. Hal ini terlihat pada pencapaian indikator kualitas penduduk yang diukur menggunakan Indeks Pembangunan Manusia (IPM). Walaupun dari tahun ke tahun pencapaian nilai IPM Nusa Tenggara Barat mengalami kenaikan, tetapi peningkatan tersebut terlihat sangat lambat.

Solusi pengendalian kuantitas penduduk akibat peningkatan LPP di Provinsi Nusa Tenggara Barat, selain menekan angka kelahiiran, yang lebih penting sebenarnya adalah pemerataan distribusi penduduk antara Pulau Lombok dengan Pulau Sumbawa.

\section{ABSTRACT}

Keyword:

Population Quantity Control
Based on population census data (SP) in 2020, West Nusa Tenggara is one of the provinces in Indonesia outside the island of Java that experienced significant population growth. Based on population projections using SUPAS, it is estimated that the rate of population growth (LPP) until 2015-2035 decreased below 1.17, but from the results of the Population Census it turned out that the LPP increased to 1.63. In addition to LPP, the total number of estimates (TFR) increased from 2.4 to 2.9.

The increase in the population of West Nusa Tenggara which tends to continue to increase from year to year will cause various increasingly complex problems. This is seen in the achievement of population quality indicators measured using the Human Development Index (HDI). Although from year to year the 
achievement of west Nusa Tenggara HDI value has increased, but the increase looks very slow.

The solution of population quantity control due to the increase in LPP in West Nusa Tenggara Province, in addition to suppressing the number of births, more important is actually the distribution of people between Lombok Island and Sumbawa Island.

\section{LATAR BELAKANG}

SP2020 mencatat penduduk Indonesia pada September 2020 sebanyak 270,20 juta jiwa. Sejak Indonesia menyelenggarakan Sensus Penduduk yang pertama pada tahun 1961, jumlah penduduk terus mengalami peningkatan. Hasil SP2020 dibandingkan dengan SP2010 memperlihatkan penambahan jumlah penduduk sebanyak 32,56 juta jiwa atau rata-rata sebanyak 3,26 juta setiap tahun

Dalam kurun waktu sepuluh tahun terakhir (2010-2020), laju pertumbuhan penduduk Indonesia sebesar 1,25 persen per tahun. Terdapat perlambatan laju pertumbuhan penduduk sebesar 0,24 persen poin jika dibandingkan dengan laju pertumbuhan penduduk pada periode 2000-2010 yang sebesar 1,49 persen.

Berbeda dengan gambaran kependudukan nasional yang laju pertumbuhan penduduknya melambat, laju pertumbuhan penduduk di Provinsi Nusa tenggara Barat justru meningkat dari 1.17 menurut SP 2010 menjadi 1.63 menurut SP 2020. Jumlah penduduk di Provinsi Nusa tenggara Barat juga meningkat 819.880 jiwa yaitu dari 4.500.212 jiwa berdasarkan SP 2010 menjadi 5.320.092 berdasarkan SP 2020.

Pertambahan penduduk Nusa Tenggara Barat yang cenderung terus meningkat dari tahun ke tahun tersebut akan menimbulkan berbagai persoalan yang semakin kompleks. Hal ini terlihat pada pencapaian indikator kualitas penduduk yang diukur menggunakan Indeks Pembangunan Manusia (IPM).
Walaupun dari tahun ke tahun pencapaian nilai IPM Nusa Tenggara Barat mengalami kenaikan, tetapi peningkatan tersebut terlihat sangat lambat. Pada tahun 2019, IPM Nusa Tenggara Barat mencapai 68,14 meningkat 0,84 dari 67,30 pada tahun 2018. Nilai IPM Provinsi Nusa Tenggara Barat masih menempati posisi 29 dari 34 Provinsi di Indonesia.

Selain persoalan kuantitas dan kualitas penduduk yang masih perlu mendapatkan perhatian serius, persoalan ketimpangan distribusi penduduk juga masih menjadi pekerjaan yang perlu diperhatikan secara serius. Saat ini, penduduk banyak bermukim di daerah-daerah pusat pertumbuhan ekonomi dan pusat pemerintahan yang menjadi magnet bagi penduduk untuk melakukan migrasi antar kabupaten/kota maupun pendatang dari luar provinsi. Ketimpangan penduduk juga terlihat dari adanya perbedaan distribusi antar wilayah dan antar pulau di Nusa Tenggara Barat. Hal ini tidak hanya berdampak pada daya dukung dan daya tampung lingkungan saja tetapi juga akan menimbulkan dampak sosial lainnya.

Sepertiga penduduk Nusa Tenggara Barat, menempati tiga perempat luas wilayah Nusa Tenggara Barat, yaitu di Pulau Sumbawa, sedangkan Pulau Lombok yang luasnya hanya seperempat wilayah Nusa Tenggara Barat, ditempati duapertiga penduduk Nusa Tenggara Barat. Sebaran penduduk antardaerah juga masih belum merata, karena sebagian penduduk Pulau Sumbawa menempati wilayah bagian 
utara, sedangkan di pulau Lombok lebih banyak penduduk menempati daerah tengah. Infrastruktur yang banyak terpusat pada kawasan tertentu akan memberi kemudahan akses bagi penduduk, baik menyangkut akses pelayanan, akses ekonomi maupun akses pembangunan lainnya. Hal ini semakin memicu pemusatan permukiman penduduk pada kawasan tertentu. Aspek geografis dan klimatologis juga menjadi pertimbangan bagi permukiman penduduk. Kawasan dengan kondisi geografis yang berada pada tingkat kelerengan tinggi serta klimatologis ekstrim, akan cenderung dihindari karena menyangkut keamanan dan kenyamanan permukiman.

Dalam upaya mengatasi berbagai persoalan yang diakibatkan oleh pertambahan penduduk tersebut maka perlu dilakukan pengendalian kuantitas penduduk sebagai bagian pembangunan kependudukan yang telah ditetapkan oleh pemerintah dalam Undang-Undang Nomor 52 Tahun 2009 tentang Perkembangan Kependudukan dan Pembangunan Keluarga yaitu:

1) Penetapan kebijakan nasional perkembangan kependudukan harus memperhatikan: a. pengendalian kuantitas penduduk; b. pengembangan kualitas penduduk; dan c. pengarahan mobilitas penduduk.

2) Pengendalian kuantitas penduduk sebagaimana dimaksud pada ayat (1) huruf a dilaksanakan melalui sinkronisasi kebijakan kependudukan di tingkat nasional dan daerah.

3) Sinkronisasi kebijakan pengendalian kuantitas penduduk sebagaimana dimaksud pada ayat (2) berhubungan dengan: a. penetapan perkiraan jumlah, struktur, dan komposisi penduduk; b. penurunan laju pertumbuhan penduduk; dan $\mathrm{c}$. persebaran penduduk
Terdapat tiga arah kebijakan yang dirumuskan dalam Pengendalian Kuantitas Penduduk, yaitu :

a. Bahwa pengendalian kuantitas penduduk dilakukan melalui penetapan perkiraan angka fertilitas, mortalitas dan mobilitas penduduk;

b. Bahwa pengendalian kuantitas penduduk dimaksudkan agar kuantitas penduduk sesuai dengan daya dukung alam dan daya tampung lingkungan;

c. Bahwa pengendalian kuantitas penduduk dilakukan tidak hanya pada tingkat Provinsi namun juga pada tingkat Kabupaten/Kota secara berkelanjutan.

Pada hakekatnya pengendalian kuantitas penduduk mempunyai tiga sasaran pokok kuantitatif, yang mencakup fertilitas, mortalitas dan persebaran penduduk. Program dan kebijakan yang telah ditetapkan oleh pemangku pengendalian kuantitas penduduk dalam jangka pendek menengah dan panjang didasarkan kepada proyeksi penurunan laju pertumbuhan penduduk yang signifikan. Namun berdasarkan SP 2020, terdapat kenaikan yang cukup signifikan. Oleh sebab itu perlu kajian untuk dapat kembali menyesuaikan berbagai hal yang terkait dengan parameter parameter pengendalian kuantitas penduduk sesuai dengan laju pertumbuhan penduduk 2020 .

\section{PEMBAHASAN}

\section{Kondisi Saat Ini}

Nusa Tenggara Barat adalah salah satu dari 34 provinsi yang ada Indonesia. Sesuai dengan namanya, provinsi ini meliputi bagian barat Kepulauan Nusa Tenggara. Dua pulau terbesar di provinsi ini adalah Lombok yang terletak di barat dan Sumbawa yang terletak di timur. Ibu kota provinsi ini adalah Kota Mataram yang berada di Pulau Lombok. 
Sebagian besar dari penduduk Lombok berasal dari suku Sasak, sementara suku Bima dan Sumbawa merupakan kelompok etnis terbesar di Pulau Sumbawa. Mayoritas penduduk Nusa Tenggara Barat beragama Islam (96\%).

Nusa Tenggara Barat yang terdiri dari Pulau Lombok dan Pulau Sumbawa, memiliki luas wilayah 20.153,15 $\mathrm{km} 2$. Terletak antara $115^{\circ} 46^{\prime}-119^{\circ} 5^{\prime}$ Bujur Timur dan $8^{\circ} 10^{\prime}-9^{\circ} \mathrm{g} 5^{\prime}$ Lintang Selatan. Selong merupakan kota yang mempunyai ketinggian paling tinggi, yaitu $148 \mathrm{~m}$ dari permukaan laut sementara Raba terendah dengan $13 \mathrm{~m}$ dari permukaan laut. Dari tujuh gunung yang ada di Pulau Lombok, Gunung Rinjani merupakan tertinggi dengan ketinggian $3.775 \mathrm{~m}$, sedangkan Gunung Tambora merupakan gunung tertinggi di Sumbawa dengan ketinggian $2.851 \mathrm{~m}$.

Jumlah penduduk Nusa Tenggara Barat berdasarkan hasil Sensus Penduduk 2010 (SP 2010) sebanyak : 4.500.212 jiwa dengan laju pertumbuhan penduduk sebesar 1,17 \%. Dengan laju pertumbuhan penduduk 1,17\% Provinsi Nusa Tenggara Barat termasuk Provinsi di Indonesia yang mampu mengendalikan laju pertumbuhan penduduknya dibawah rata-rata Nasional sebesar 1,49\%. Jumlah penduduk yang cukup besar ini, diringi dengan pula dengan laju pertumbuhan penduduk (LPP) yang masih cukup tinggi yaitu $1,17 \%$ per tahun pada periode tahun 2000-2010, namun bila dibandingkan dengan laju pertumbuhan penduduk periode sebelumnya yaitu periode tahun 19902000 terjadi penurunan sebesar $\mathbf{0 , 1 2} \%$ dari laju pertumbuhan penduduk periode sebelumnya (1990-2000) yang tercatat sebesar $\mathbf{1 , 2 9 \%}$.

Tabel 1.

Laju Pertumbuhan Penduduk Kabupaten/Kota se Nusa Tenggara Barat

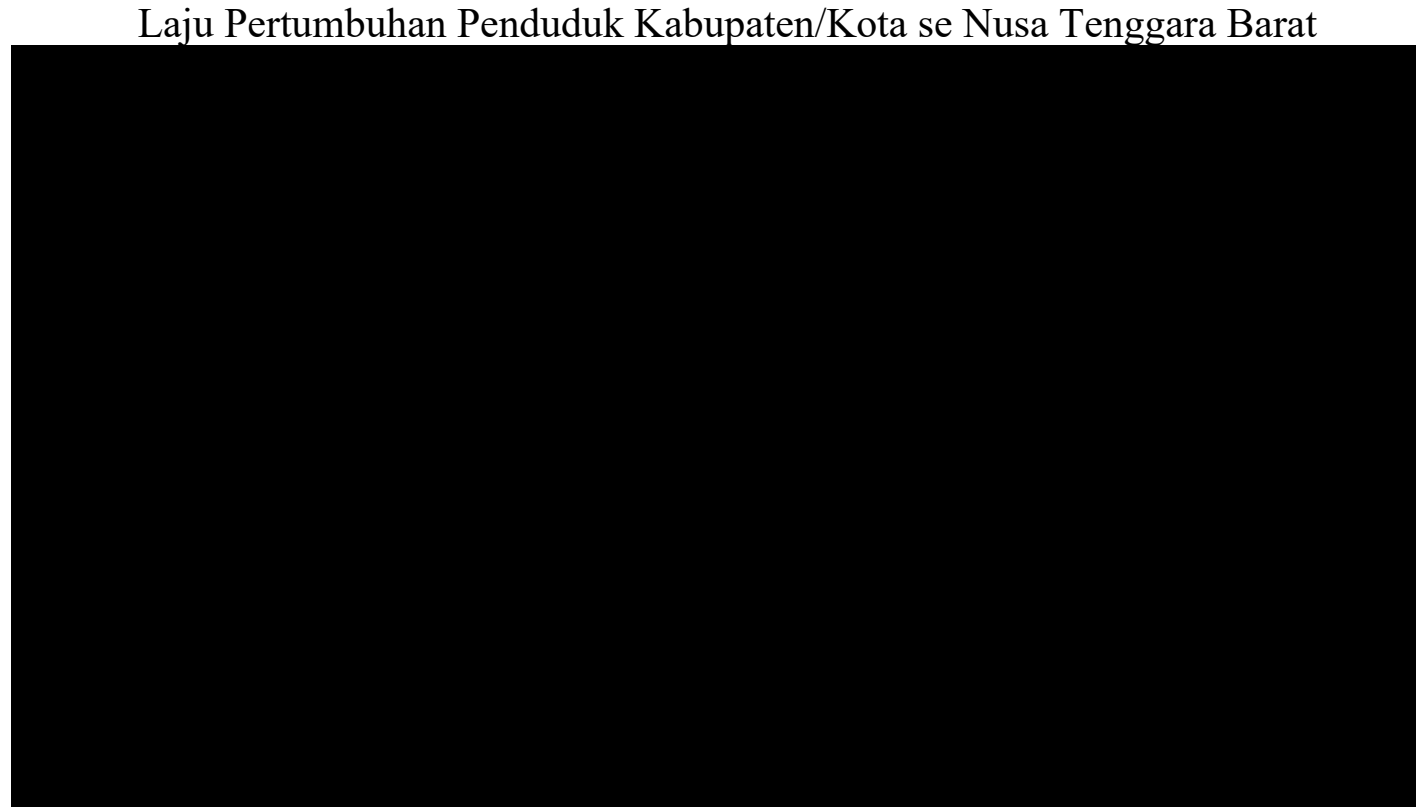

Sumber : BPS Prov. NTB

Dengan laju pertumbuhan penduduk $1,17 \%$ maka dilakukan proyeksi penduduk sampai dengan 2045. Pada tahun 2020 ini diperkirakan jumlah penduduk Nusa Tenggara Barat akan bertambah menjadi: 5.225.9 jiwa dan akan menjadi 6.710 .3 jiwa pada tahun 2045. Untuk lengkapnya dapat dilihat dalam tabel gambar berikut: 
Tabel 2.

Proyeksi Penduduk NTB 2015-2045 Berdasarkan Data SUPAS 2005-2015

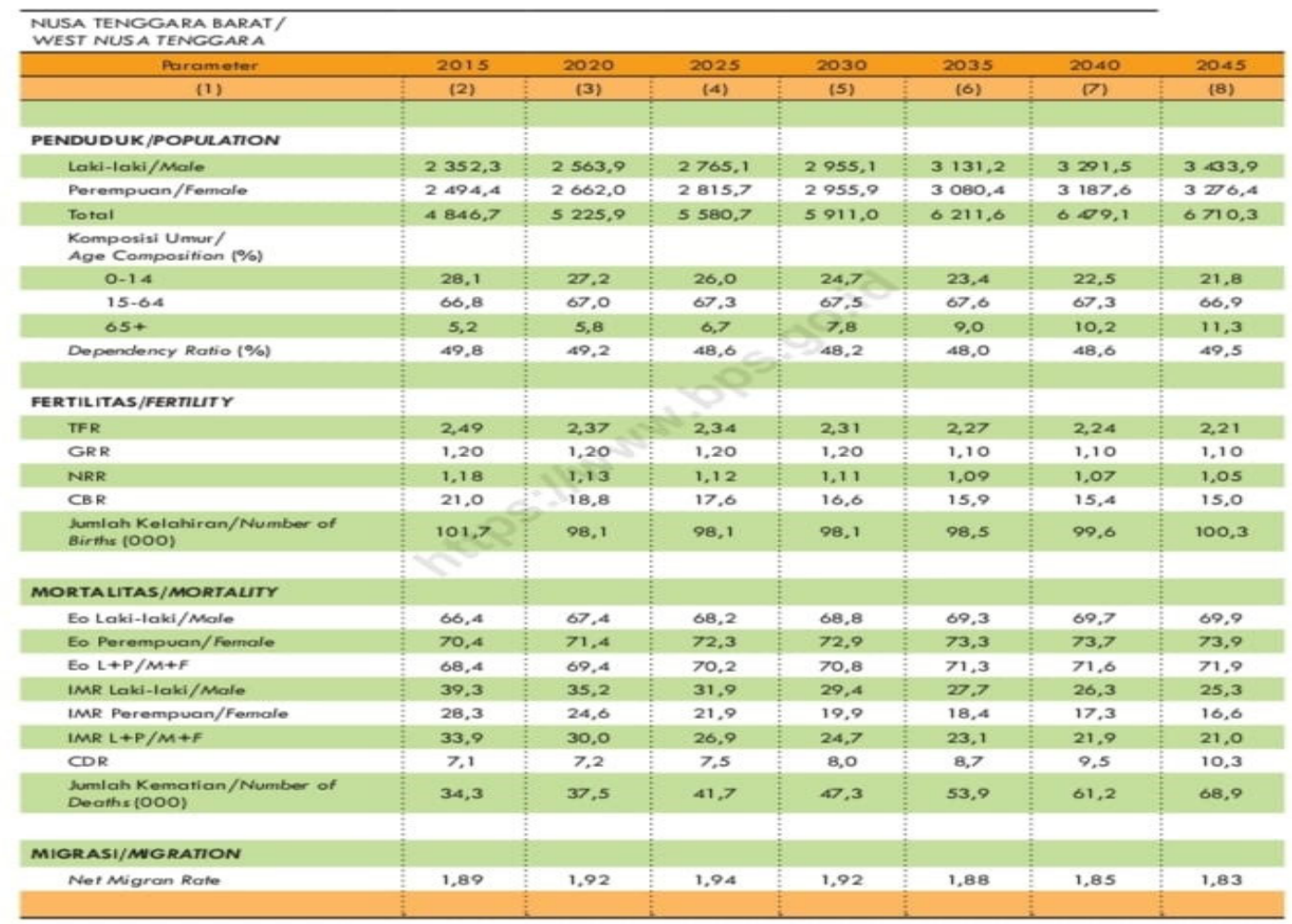

Sumber: Data Bappenas RI

Hasil proyeksi penduduk selanjutnya akan dikonfirmasi berdasarkan data riil berikutnya. Data Sensus Penduduk Tahun 2010 yang telah digunakan untuk memproyeksi jumlah penduduk pada 2015-2045 dapat dilihat keakuratannya pada saat Data Sensus berikutnya yaitu Sensus Penduduk Tahun 2020 .

Berdasarkan hasil Sensus Penduduk 2020, Laju pertumbuhan penduduk yang diproyeksi 1.13 persen ternyata meningkat cukup signifikan yaitu 1.63 persen. Begitu pula dengan jumlah penduduk yang diproyeksi berjumlah 5.133.049 jiwa, berdasarkan Sensus Penduduk 2020 berjumlah 5320092 jiwa

Data lain yang terkonfirmasi dari Sensus Penduduk 2020 adalah data TFR yang diproyeksi sebesar 2.37 per wanita ternyata meningkat menjadi 2.90 per wanita

Gambar 1. Ringkasan Hasil Sensus 2020 Provinsi NTB 


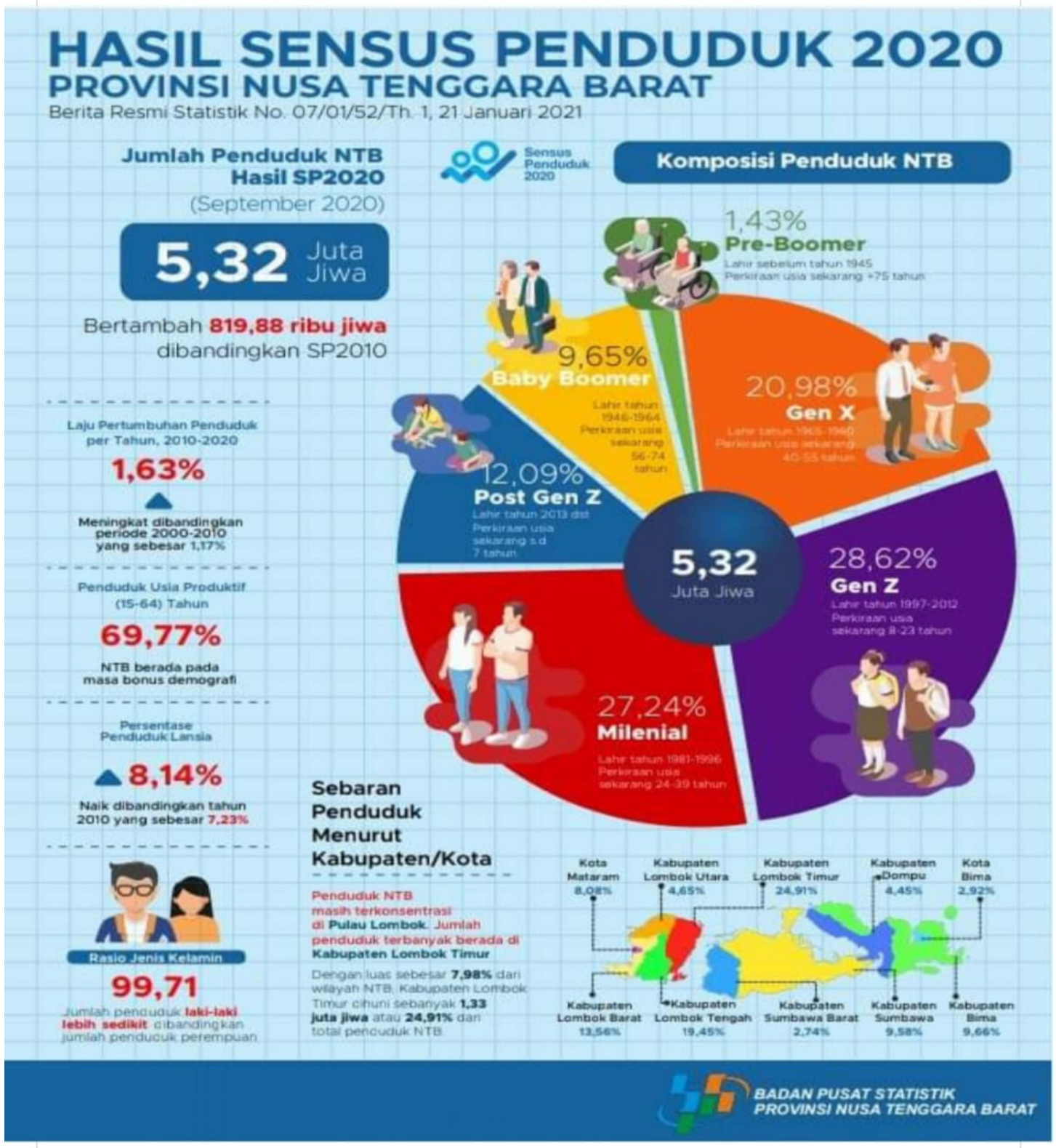

\section{Proyeksi Penduduk}

Berdasarkan data Sensus

Penduduk tahun 2010 dan tahun 2020 dan menggunakan metode Proyeksi
Aritmatika, maka diperoleh proyeksi jumlah penduduk di Provinsi Nusa Tenggara Barat tahun 2025-2045 sbb:

Tabel 2.

Proyeksi Penduduk Berdasarakan Data Sensus 2010-2020

\begin{tabular}{|l|r|r|r|r|r|r|r|}
\hline Wilayah & \multicolumn{1}{c|}{$\mathbf{2 0 1 0}$} & \multicolumn{1}{c|}{$\mathbf{2 0 2 0}$} & \multicolumn{1}{c|}{$\mathbf{2 0 2 5}$} & \multicolumn{1}{c|}{$\mathbf{2 0 3 0}$} & \multicolumn{1}{c|}{$\mathbf{2 0 3 5}$} & \multicolumn{1}{c|}{$\mathbf{2 0 4 0}$} & \multicolumn{1}{c|}{$\mathbf{2 0 4 5}$} \\
\hline P. Lombok & $3,168,692$ & $3,758,645$ & $4,108,541$ & $4,458,437$ & $4,808,332$ & $5,158,228$ & $5,508,124$ \\
\hline Lobar & 599,986 & 721,404 & 794,399 & 867,394 & 940,389 & $1,013,384$ & $1,086,379$ \\
\hline Loteng & 860,209 & $1,034,758$ & $1,139,742$ & $1,244,725$ & $1,349,709$ & $1,454,693$ & $1,559,676$ \\
\hline Lotim & $1,105,582$ & $1,325,235$ & $1,456,881$ & $1,588,528$ & $1,720,174$ & $1,851,820$ & $1,983,467$ \\
\hline Mataram & 402,843 & 429,863 & 444,280 & 458,696 & 473,113 & 487,529 & 501,945 \\
\hline KLU & 200,072 & 247,384 & 276,635 & 305,885 & 335,135 & 364,385 & 393,636 \\
\hline
\end{tabular}




\begin{tabular}{|l|c|r|r|r|r|r|r|}
\hline \multicolumn{1}{|c|}{ Wilayah } & $\mathbf{2 0 1 0}$ & \multicolumn{1}{c|}{$\mathbf{2 0 2 0}$} & $\mathbf{2 0 2 5}$ & \multicolumn{1}{c|}{$\mathbf{2 0 3 0}$} & \multicolumn{1}{c|}{$\mathbf{2 0 3 5}$} & \multicolumn{1}{c|}{$\mathbf{2 0 4 0}$} & \multicolumn{1}{c|}{$\mathbf{2 0 4 5}$} \\
\hline P. Sumbawa & $1,331,520$ & $1,561,447$ & $1,696,262$ & $1,831,078$ & $1,965,893$ & $2,100,709$ & $2,235,524$ \\
\hline SBW & 415,789 & 509,665 & 567,200 & 624,736 & 682,271 & 739,807 & 797,342 \\
\hline Dompu & 218,973 & 236,744 & 246,351 & 255,957 & 265,564 & 275,171 & 284,777 \\
\hline Bima & 439,228 & 513,921 & 557,618 & 601,316 & 645,013 & 688,710 & 732,408 \\
\hline Kobi & 142,579 & 155,347 & 162,302 & 169,258 & 176,213 & 183,169 & 190,124 \\
\hline KSB & 114,951 & 145,771 & 165,312 & 184,853 & 204,394 & 223,936 & 243,477 \\
\hline NTB & $4,500,212$ & $5,320,092$ & $5,804,718$ & $6,289,343$ & $6,773,969$ & $7,258,595$ & $7,743,221$ \\
\hline
\end{tabular}

\section{Sumber: Data Diolah}

\section{Kondisi yang Diinginkan Dan Roadmap 2025-2045}

Pengendalian jumlah penduduk sebenarnya sangat tergantung daya dukung dan daya tampung lingkungannya. Untuk Provinsi Nusa Tenggara Barat yang penduduknya sebagian besar dari sektor pertanian maka daya dukung pertanian dan daya tampungnya menjadi sangat penting. Terkait dengan pengendalian kuantitas penduduk maka daya tampung dengan pendekatan kepadatan penduduk dapat dilakukan.

Jika diasumsikan kepadatan ideal sebuah wilayah adalah 250 jiwa per $\mathrm{km} 2$, maka jumlah penduduk Nusa Tenggara Barat adalah sbb:

Tabel 3.

Pengendalian Kuantitas Penduduk dan Roadmap 2025-2045

\begin{tabular}{|l|r|r|r|r|r|r|r|}
\hline \multicolumn{1}{|c|}{ Wilayah } & \multicolumn{1}{c|}{$\begin{array}{c}\text { Luas } \\
\text { (Km2) }\end{array}$} & \multicolumn{1}{c|}{$\mathbf{2 5 0 / \mathbf { k m 2 }}$} & \multicolumn{1}{c|}{$\mathbf{2 0 2 5}$} & \multicolumn{1}{c|}{$\mathbf{2 0 3 0}$} & \multicolumn{1}{c|}{$\mathbf{2 0 3 5}$} & \multicolumn{1}{c|}{$\mathbf{2 0 4 0}$} & \multicolumn{1}{c|}{$\mathbf{2 0 4 5}$} \\
\hline P. Lombok & $4,738.60$ & $1,184,650.00$ & $2,923,891$ & $3,273,787$ & $3,623,682$ & $3,973,578$ & $4,323,474$ \\
\hline Lobar & $1,053.90$ & $263,475.00$ & 530,924 & 603,919 & 676,914 & 749,909 & 822,904 \\
\hline Loteng & $1,208.40$ & $302,100.00$ & 837,642 & 942,625 & $1,047,609$ & $1,152,593$ & $1,257,576$ \\
\hline Lotim & $1,605.50$ & $401,375.00$ & $1,055,506$ & $1,187,153$ & $1,318,799$ & $1,450,445$ & $1,582,092$ \\
\hline Mataram & 61.30 & $15,325.00$ & 428,955 & 443,371 & 457,788 & 472,204 & 486,620 \\
\hline KLU & 809.50 & $202,375.00$ & 74,260 & 103,510 & 132,760 & 162,010 & 191,261 \\
\hline P. Sumbawa & $15,414.50$ & $3,853,625.00$ & $-2,157,363$ & $-2,022,547$ & $-1,887,732$ & $-1,752,916$ & $-1,618,101$ \\
\hline SBW & $6,643.98$ & $1,660,995.00$ & $-1,093,795$ & $-1,036,259$ & $-978,724$ & $-921,188$ & $-863,653$ \\
\hline Dompu & $2,324.60$ & $581,150.00$ & $-334,799$ & $-325,193$ & $-315,586$ & $-305,979$ & $-296,373$ \\
\hline Bima & $4,389.40$ & $1,097,350.00$ & $-539,732$ & $-496,034$ & $-452,337$ & $-408,640$ & $-364,942$ \\
\hline Kobi & 207.50 & $51,875.00$ & 110,427 & 117,383 & 124,338 & 131,294 & 138,249 \\
\hline KSB & $1,849.02$ & $462,255.00$ & $-296,943$ & $-277,402$ & $-257,861$ & $-238,319$ & $-218,778$ \\
\hline NTB & $20,153.10$ & $5,038,275.00$ & 766,443 & $1,251,068$ & $1,735,694$ & $2,220,320$ & $2,704,946$ \\
\hline
\end{tabular}

Sumber Data Diolah

Jika daya dukung dan daya tampung wilayah Provinsi Nusa Tenggara Barat menggunakan pendekatan Indek Kepadatan Penduduk (IKP) dan jika jumlah ideal kepadatan penduduk sebanyak 250 jiwa/Km2, maka jumlah penduduk yang layak tinggal di Provinsi Nusa Tenggara Barat adalah sebanyak 5.038.275. dengan distribusi $23.51 \%$ mendiami Pulau Lombok dan $76.49 \%$ mendiami Pulau Sumbawa.

\section{PENUTUP}

Berdasarkan data tersebut maka pengendalian kuantitas penduduk di Provinsi Nusa Tenggara Barat sebagian 
besar adalah dengan melakukan pemindahan penduduk dari Pulau Lombok ke Pulau Sumbawa dan sebagian kecil adalah memindahkannya/transmigrasi ke luar provinsi Nusa Tenggara Barat dengan tetap menekan laju pertumbuhan penduduk melalui program Keluarga Berencana.

\section{REFERENSI}

Bappenas.go.id

BPS NTB.go.id

BPS Pusat.go.id 